\title{
THERAPEUTIC EFFECTS OF CARBOGEN THERAPY IN SUDDEN SENSORINEURAL HEARING LOSS
}

\author{
Shaili Priyamvada1, Rajeev Yande ${ }^{2}$
}

${ }^{1}$ Senior Resident, Department of ENT, VMMC and Safdarjung Hospital, New Delhi, India; Ex-Resident, Ruby Hall Clinic, Pune, Maharashtra, India.

2Senior Consultant, Department of ENT, Jehangir Hospital, Pune, Maharashtra, India; Ex-Consultant, Ruby Hall Clinic, Pune, Maharashtra, India.

ABSTRACT
BACKGROUND
Sudden Hearing Loss (SHL) is a rare disease accounting for $1 \%$ of all sensorineural hearing loss cases, but it is considered an
otological emergency. The sooner the treatment begins, the outcome proves to be better. Different theories have been postulated
with regard to determining its cause. Most accepted treatment at the present time is systemic steroid therapy.
The purpose of our study was to compare the efficacy of carbogen therapy combined with steroids, is whether or not superior to
steroids alone in the treatment of sudden hearing loss.

\section{MATERIALS AND METHODS}

This prospective, non-randomised, controlled parallel trial included 60 patients with idiopathic SHL who visited our clinic within 14 days of symptom onset between August 2013 and February 2015. All patients received oral prednisolone for 10 days. Of the 60 patients, 30 received no additional treatment and 30 received additional carbogen inhalation. Hearing improvement was measured using Siegel's criteria.

\section{RESULTS}

We observed in our study that complete recovery at two months occurred in $33.33 \%$ and $26.67 \%$ subjects in Group 1 [Carbogen therapy plus steroids] and Group 2 [steroids alone] correspondingly. As for partial recovery, 53.33\% and 66.67\% in Group 1 and 2 correspondingly (Siegel's criteria 1 and 2). Slight improvement was noticed as follows at $10^{\text {th }}$ sitting $23.33 \%$ and $13.33 \%$ and at 2 months $13.33 \%$ and $6.67 \%$ in corresponding group. Though these results show that carbogen therapy is better than steroids, the data is calculated to be statistically insignificant using Fisher's exact test ( $\mathrm{p}$-value 0.267 and $0.591>0.05$ ). We also found that there is statistically significant [p-value 0.01] association between age of onset of sensorineural hearing loss and betterment of hearing. Younger the age at the time of onset of hearing loss, there are better chances of hearing gain towards normal hearing sensitivity.

\section{CONCLUSION}

Carbogen inhalation added to steroids was a more effective treatment than steroids alone in patients with idiopathic sudden sensorineural hearing loss.

\section{KEY WORDS}

Sudden Sensorineural Hearing Loss, Carbogen Therapy, Steroids.

HOW TO CITE THIS ARTICLE: Priyamvada S, Yande R. Therapeutic effects of carbogen therapy in sudden sensorineural hearing loss. J. Evolution Med. Dent. Sci. 2018;7(35):3878-3882, DOI: 10.14260/jemds/2018/868

\section{BACKGROUND}

Sudden Hearing Loss (SHL) is defined as sensorineural hearing loss of $30 \mathrm{~dB}$ or more in three sequential frequencies occurring over 3 days or less. ${ }^{1}$ SHL was first reported by De Kleyn ${ }^{2}$ in 1944 and there have been many studies regarding SHL, but the pathogenesis remains unclear.

Idiopathic Sudden Sensorineural Hearing Loss [SSNHL] has an estimated incidence of 5 to 20 per 100,000 persons per year. ${ }^{3}$ SHL involves a variety of causative factors and therefore should be considered a syndrome rather than a single disease ${ }^{4}$ and it accounts for $1 \%$ of all sensorineural hearing loss cases. ${ }^{4}$ Males are equally affected as females. ${ }^{5}$ About one-third of people with SHL awaken in the morning with a hearing loss.

'Financial or Other Competing Interest': None.

Submission 12-07-2018, Peer Review 10-08-2018,

Acceptance 16-08-2018, Published 27-08-2018.

Corresponding Author:

Dr. Rajeev Yande,

Jeevan Sadhna Clinic,

Near Yatri Hotel, Karve Road,

Pune-411029, Maharashtra, India.

E-mail:drrdyande@gmail.com

DOI: $10.14260 /$ jemds $/ 2018 / 868$

\section{(c) $(\mathbf{P}) \Theta$}

By definition, the aetiology of ISSNHL is unknown. Different theories have been postulated. The majority of treatment modalities are based on two common theories of aetiologies: - Circulatory disturbances and inflammatory reaction, most commonly viral infection. SSNHL is a diagnosis of exclusion. Clinical evaluation and examination are of utmost importance to rule out organic causes of sudden hearing loss.

Sudden sensorineural hearing loss is considered to be a true otologic emergency, given the observation that there is less recovery of hearing when treatment is delayed. There are no published guidelines for evaluation or management of sudden sensorineural hearing loss. The lack of a standard definition for SSNHL, lack of a standard method for audiological assessment with regard to the configuration of hearing loss and hearing recovery, low incidence rate and the fact that spontaneous recovery occurs in upto $65 \%$ of cases make any evaluation and treatment difficult for an otolaryngologist. ${ }^{6}$ From a therapeutic point of view the most widely accepted treatment for SHL is systemic corticosteroids, ${ }^{7}$ due to their ability to reduce inflammation, inhibit immune mechanisms and regulate electrolyte balance. Oral corticosteroid therapy is among the few treatment 
modalities that have gained acceptance and proved to be effective in selected studies. However, studies have shown that corticosteroid treatment is not significantly more effective than placebo and includes adverse effects. ${ }^{8}$

Thus, there have been continuous efforts to identify additional treatments. In case of SHL caused by viral infection, studies on antiviral therapy have shown controversial therapeutic results. ${ }^{9}$

Carbogen therapy is one of them which acts by inhalation, increases arterial oxygen saturation and maximises oxygen supply to the inner ear. ${ }^{10}$ Studies on the effects of carbogen therapy in SHL have shown controversial results. Shea and Kitabchi ${ }^{11}$ reported that carbogen inhalation had a therapeutic effect, while Cinamon et $\mathrm{al}^{8}$ found no therapeutic effect. Similarly, Zhao et al12 reported that Lipo-PGE1 had a therapeutic effect, while Ahn et al ${ }^{13}$ found no therapeutic effect. Despite controversial benefits, the theories remain that improving circulation may yield therapeutic results in cases where a vascular disorder underlies the SHL.

In this study, we compared two modalities of treatment options for SHL, carbogen inhalation combined with steroids to the steroids alone.

\section{Aims and Objectives}

Compare the efficacy of carbogen therapy combined with steroids, is whether or not superior to steroids alone in the treatment of sudden hearing loss.

\section{MATERIALS AND METHODS}

We have conducted the pilot survey of 10 patients for each group by considering the mean hearing loss at 10th sitting 34.15 (Group 1) and 37.41 (Group 2) with standard deviation of 13.35 and 12.47 .

Sample size calculated by using 2 independent sample mean Total Sample size is (N) $=4^{*}(\mathrm{M} 1-\mathrm{M} 2) /(\mathrm{SD}){ }^{\wedge} 2$

Where, M1 is mean group $1, \mathrm{M} 2$ is mean group 2 $\mathrm{SD}=$ Standard deviation, Total Sample size is 63 .

We studied 60 patients, who visited the outpatient department. It was a prospective non-randomised controlled parallel trial. Ruby Hall Clinic hospital is amongst one of the limited set-ups where carbogen therapy is administered; hence, we get referred patients of ISSNHL both from peripheries and the city itself. Patients of either sex between age group 15 - 65 years were included, who sustained sudden unilateral hearing loss in $72 \mathrm{hrs}$. or less duration and presented to us within 14 days of beginning of symptoms. Patients with similar history in past, local trauma, previous ear surgeries or having systemic illnesses were excluded. Patients were allocated in two groups, 1, 3, 5, 7.... in Group 1 and 2, 4, 6, 8...so on in Group 2. All patients underwent a thorough history and physical examination, pure tone audiometry, speech audiometry and impedance audiometry. Informed consent was obtained from all individuals and were included in the study.

Group 2 received oral prednisolone $1 \mathrm{mg} / \mathrm{kg}$ body wt. for 5 days and tapered over next 5 days $\left(60 \mathrm{mg} 1^{\text {st }} 5\right.$ days, $30 \mathrm{mg}$ day 6 and 7, $10 \mathrm{mg}$ last three days) and Group 1 received additional inhalation of carbogen $\left(5 \% \mathrm{CO}_{2}+95 \% \mathrm{O}_{2}\right.$ mixture $)$. Carbogen therapy was administered to the patient for 30 minutes daily for 5 days using Magill's circuit and anatomical facemask by setting a flow of 5 litres/min of 02 and 250
$\mathrm{mL} / \mathrm{min}$ of CO2. Patient was monitored throughout and signs and symptoms of $\mathrm{CO} 2$ retention such as sweating, tachycardia or hypertension were observed.

Patients were evaluated for hearing gain by taking pure tone average at $0.5,1$ and $2 \mathrm{kHz}$ pre-therapy at the time of presentation and post therapy. Patients in Group 1 underwent follow-up audiometry after $5^{\text {th }}$ sitting and $10^{\text {th }}$ sitting of carbogen therapy; as for Group 2 patients pre-therapy audiometry and post-therapy after 10 days. All patients were called on request at 2 months and pure tone audiometry was repeated and pure tone averages compared with previous results.

\section{Statistical Analysis}

Statistical analysis was done using Stata version 10 (StataCorp, Texas and USA). Students' test, Chi-square test and Fisher's 'exact' test was used for categorical variables.

\begin{tabular}{|c|c|}
\hline Type & Hearing Recovery \\
\hline I. Complete recovery & Final hearing better than $25 \mathrm{~dB}$ \\
\hline II. Partial recovery & $\begin{array}{c}\text { More than } 15 \mathrm{~dB} \text { gain, final } \\
\text { hearing } 25-45 \mathrm{~dB}\end{array}$ \\
\hline III. Slight improvement & $\begin{array}{c}\text { More than } 15 \mathrm{~dB} \text { gain, final } \\
\text { hearing poorer than } 45 \mathrm{~dB}\end{array}$ \\
\hline IV. No improvement & $\begin{array}{c}\text { Less than } 15 \mathrm{~dB} \text { gain, final } \\
\text { hearing poorer than } 75 \mathrm{~dB}\end{array}$ \\
\hline \multicolumn{2}{|c|}{ Table 1. Siegel's Criteria of Hearing Recovery } \\
\hline
\end{tabular}

\section{RESULTS}

\section{Patient's Characteristics}

Out of 60 patients included in our study, 29 were males and 31 were females. Their mean age was $41.73 \pm 16.71$ for Group 1 and $38.73 \pm 12.91$ for Group 2 (range 15 - 65 years). The average time between onset of symptoms and presenting to clinic in two groups were $6.3 \pm 3.21$ and $6.93 \pm 2.61$ in Group 1 and 2 respectively. There was no significant difference in age, gender, mean duration of SHL, mean threshold of hearing loss, follow-up period, laterality of ear affected and disease symptoms between the two groups.

\begin{tabular}{|c|c|c|c|}
\hline \multirow{2}{*}{ Age Group } & \multicolumn{2}{|c|}{ Group } & \multirow{2}{*}{ Total } \\
\cline { 2 - 3 } & Group 1 & Group 2 & \\
\hline$\leq 20$ & 4 & 3 & 7 \\
\hline $21-30$ & 5 & 6 & 11 \\
\hline $31-40$ & 7 & 8 & 15 \\
\hline $41-50$ & 7 & 9 & 16 \\
\hline $51-60$ & 6 & 3 & 9 \\
\hline$>60$ & 1 & 1 & 2 \\
\hline Total & $\mathbf{3 0}$ & $\mathbf{3 0}$ & $\mathbf{6 0}$ \\
\hline Table 2a. Comparison of Age (in years) in Group 1 and \\
Group 2 \\
\hline
\end{tabular}

\begin{tabular}{|c|c|c|c|c|}
\hline & Number of & \multicolumn{2}{|c|}{ Age (Years) } & \multirow{2}{*}{ P-value } \\
\cline { 3 - 4 } & Patients & Mean & SD & \\
\hline Group 1 & 30 & 41.73 & 16.71 & \multirow{2}{*}{0.440} \\
\hline Group 2 & 30 & 38.73 & 12.91 & \\
\hline 2b. Comparison of Age (in years) in Group 1 and Group 2 \\
\hline
\end{tabular}

By using 2 independent sample t-test p-value $>0.05$, therefore there is no significant difference between mean age (years) in Group 1 and Group 2. 


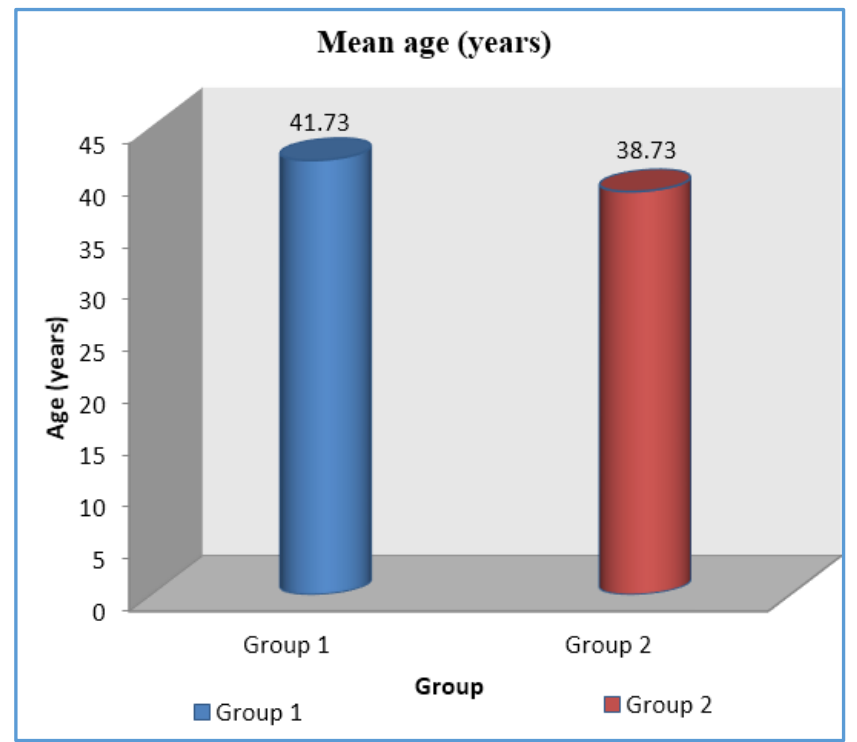

Figure 1. Comparison of Mean Age in Two Groups

\begin{tabular}{|c|c|c|c|c|c|}
\hline \multirow{2}{*}{ HL } & \multicolumn{2}{|c|}{ Group 1 (n= 30) } & \multicolumn{2}{c|}{ Group 2 (n= 30) } & \multirow{2}{*}{ P-value } \\
\cline { 2 - 6 } & Mean & SD & Mean & SD & \\
\hline At baseline & 61.19 & 15.62 & 59.31 & 10.85 & 0.59 \\
\hline At 10th setting & 34.16 & 13.32 & 37.53 & 12.36 & 0.313 \\
\hline At 2nd month & 32.63 & 13.09 & 34.00 & 11.37 & 0.668 \\
\hline Table 3. Comparison of Mean HL in Group 1 and Group 2 \\
\hline
\end{tabular}

By using 2 independent sample t-test $p$-value $>0.05$, therefore there is no significant difference between mean HL in Group 1 and Group 2.

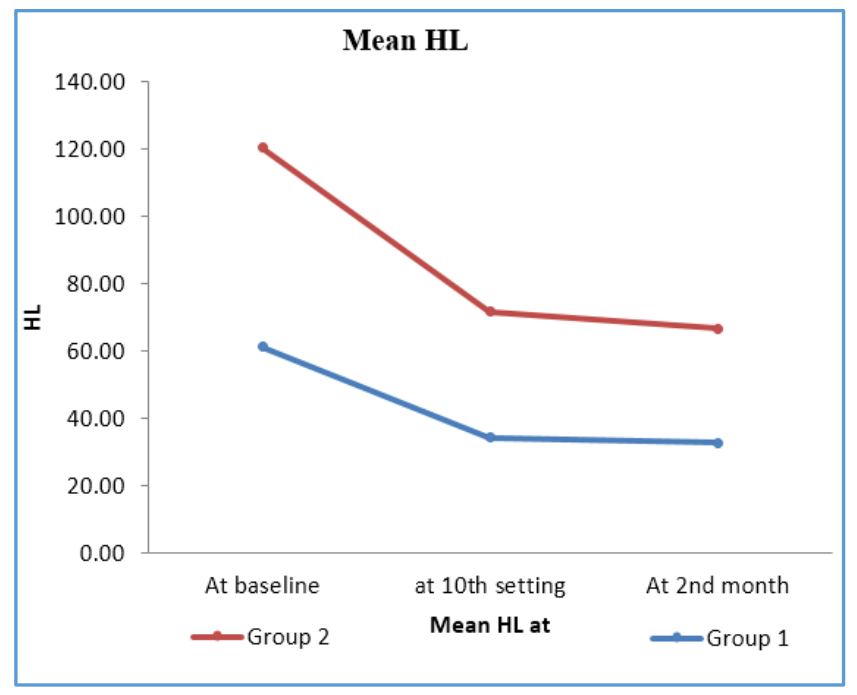

Figure 2. Comparison of Mean $\mathrm{HL}$ in Group 1 and Group 2

\begin{tabular}{|c|c|c|c|c|c|}
\hline & \multicolumn{2}{|c|}{ Group 1 } & \multicolumn{2}{c|}{ Group 2 } & \multirow{2}{*}{ P-value } \\
\cline { 2 - 6 } & Mean & SD & Mean & SD & - \\
\hline RHG at 5th sitting & 8.93 & 7.24 & - & - & - \\
\hline $\begin{array}{c}\text { RHG at 10th } \\
\text { sitting }\end{array}$ & 27.03 & 11.79 & 21.78 & 11.83 & 0.09 \\
\hline $\begin{array}{c}\text { RHG at 2nd } \\
\text { month }\end{array}$ & 28.56 & 11.45 & 25.31 & 11.58 & 0.279 \\
\hline $\begin{array}{c}\text { Table 4. Comparison of Mean of Relative Hearing Gain in } \\
\text { Two Groups }\end{array}$ \\
\hline
\end{tabular}

By using 2 independent sample t-test p-value $>0.05$, therefore there is no significant difference between mean change in $\mathrm{HL}$ at $10^{\text {th }}$ sitting and $2^{\text {nd }}$ month.

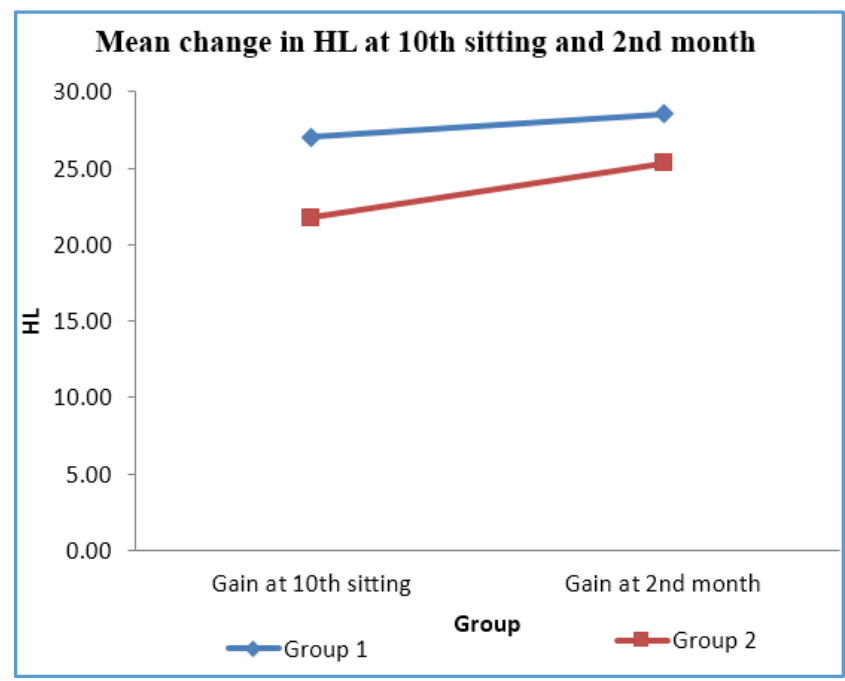

Figure 3. Comparison of Mean of Relative Hearing Gain in Two Groups

\begin{tabular}{|c|c|c|c|c|c|c|c|}
\hline & \multicolumn{4}{|c|}{ Siegel's Criteria } & \multirow[b]{2}{*}{$\stackrel{7}{\stackrel{7}{0}}$} & \multirow[b]{2}{*}{ فํ. } \\
\hline & & 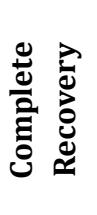 & 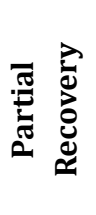 & 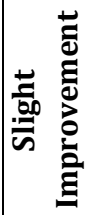 & 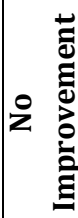 & & \\
\hline \multirow{2}{*}{$\begin{array}{c}\text { 5th } \\
\text { sitting }\end{array}$} & Group 1 & 0 & 11 & 19 & 0 & 30 & \multirow{2}{*}{-} \\
\hline & Group 2 & 0 & 0 & 0 & 0 & 0 & \\
\hline \multirow{2}{*}{$\begin{array}{l}\text { 10th } \\
\text { sitting }\end{array}$} & Group 1 & 9 & 14 & 7 & 0 & 30 & \multirow{2}{*}{0.267} \\
\hline & Group 2 & 5 & 20 & 4 & 1 & 30 & \\
\hline \multirow{2}{*}{$\begin{array}{c}\text { 2nd } \\
\text { month }\end{array}$} & Group 1 & 10 & 16 & 4 & 0 & 30 & \multirow{2}{*}{0.591} \\
\hline & Group 2 & 8 & 20 & 2 & 0 & 30 & \\
\hline
\end{tabular}

By using Fisher's exact test p-value $>0.05$, therefore there is no significant association between Siegel's grade with Group 1 and Group 2.

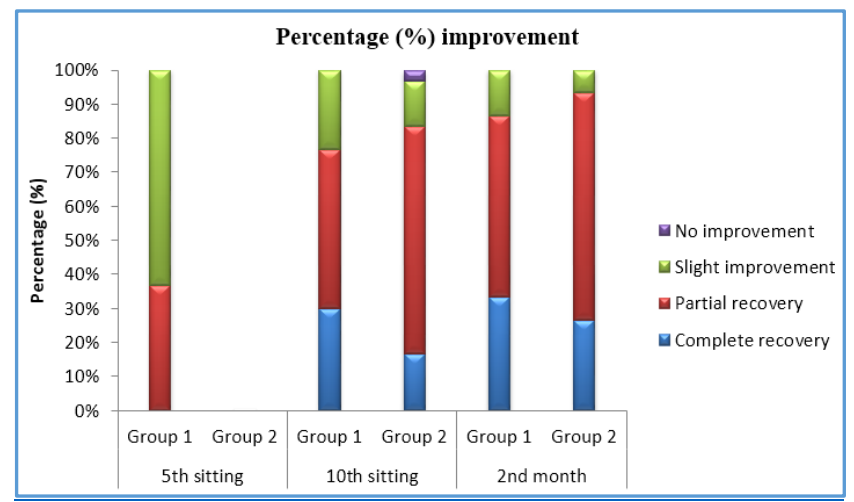

Figure 4. Comparison of \% of improvement in Corresponding Group 


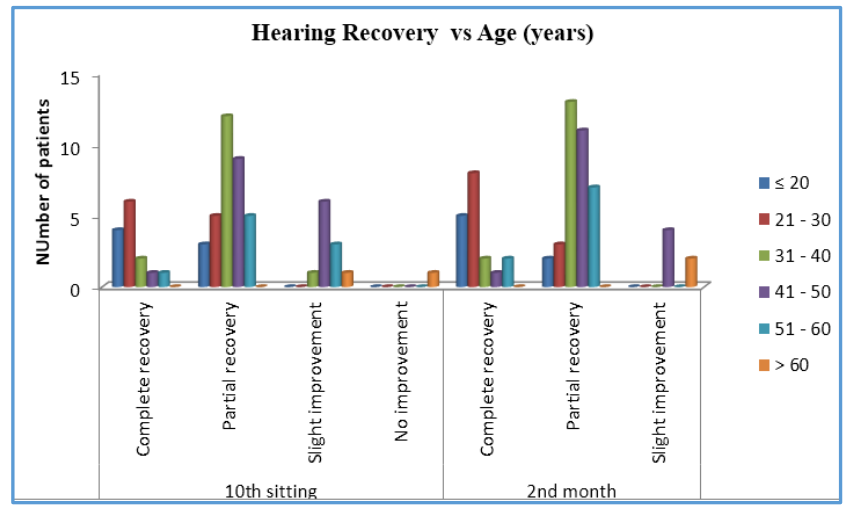

Figure 5. Comparison of Outcome based on Age of Incidence of ISSNHL

\section{Hearing Change}

We observed in our study that complete recovery at two months occurred in $33.33 \%$ and $26.67 \%$ subjects in Group 1 and 2 correspondingly.

As for partial recovery, $53.33 \%$ and $66.67 \%$ in Group 1 and 2 correspondingly (Siegel's criteria 1 and 2).

Slight improvement was noticed as follows- at 10th sitting $23.33 \%$ and $13.33 \%$ and at 2 months $13.33 \%$ and $6.67 \%$ in corresponding group.

We also found that after initiating carbogen post $5^{\text {th }}$ sitting of therapy, there was hearing improvement of $33.67 \%$ (Partial recovery) and $66.33 \%$ (Slight improvement) in the carbogen group (Table 5).

Though these results show that carbogen therapy is better than steroids, the data is calculated to be statistically insignificant using Fisher's exact test (p-value 0.267 and 0.591 $>0.05$ ).

In regard to the average relative hearing gain, i.e. RHG (hearing difference between pre- and post-pure tone threshold) was $27.03 \pm 11.79$ on $10^{\text {th }}$ day and $28.56 \pm 11.45$ at 2 months in Group 1, correspondingly it was $21.78 \pm 11.83$ and $25.31 \pm 11.58$ in Group 2 .

By comparing this data, carbogen group has higher RHG as compared to steroid only group both at 10 days and 2 months follow-up. But there was no statistically significant difference found using independent sample student t-test between RHG at $10^{\text {th }}$ sitting and $2^{\text {nd }}$ month in Group 1 and Group 2 (p-values 0.09 and $0.279>0.05$ ).

\section{Outcome based on Age}

We also observed that the patients who had ISSNHL at older age showed poorer hearing improved as compared to younger age group of patients, both at 10th day and 2nd month of follow-up. This data by using Fisher's exact test is calculated to be significant statistically and hence there is association between hearing outcome with increasing age ( $p$ value $=0.01$ i.e. $<0.05)$.

\section{Complications}

There were no major complications during our treatment. Vitals were monitored for all the patients throughout carbogen sittings and were stable. We did not observe tachycardia, hypertension or sweating for any of our patients. Few of the patients complained of feeling of suffocation on starting of $\mathrm{CO}_{2}$ gas, which weaned off in $5-10$ seconds of discontinuation.

\section{DISCUSSION}

Although, the underlying mechanism of SHL is unknown, the most common causes are thought to be vascular disorders and inflammatory reactions due to viral insult of the inner ear. Antivirals have been proposed to treat SHL caused by a viral infection, although Stokroos et $\mathrm{al}^{9}$ found no significant difference in recovery between patients receiving acyclovir (68\% of 22 patients) and those in the control group (43\% of 21 patients). Furthermore, Westerlaken et al ${ }^{14}$ reported that antiviral treatment had no effect on hearing gain.

Lee $\mathrm{HJ}$ et al ${ }^{15}$ in 2012 retrospectively reviewed 202 patients with idiopathic SHL. In their study, it was concluded that Carbogen inhalation added to steroid was a more effective treatment than Lipo-PGE1 added to steroid or steroid alone in patients with SHL. Chaturvedi et al ${ }^{16}$ in 1990 studied therapeutic role of carbogen therapy evaluated in subjects with sensorineural hearing loss and significant improvement was observed both in air and bone conduction threshold levels on seventh day of carbogen administration. They concluded that improvement in hearing may be due to action of $\mathrm{CO} 2$ as an otic vasodilator coupled with supplementation of the 02 requirement of degenerating hair cells.

Carbogen inhalation therapy (inhalation of a mixture of $5 \% \mathrm{CO}_{2}$ and $95 \% \mathrm{O}_{2}$ ) is based on the theory that carbon dioxide causes vasodilation, increasing blood flow and oxygen to the injured hair cells of cochlear and inner ear structures. According to a study on therapeutic gas proportions, arterial $\mathrm{CO}_{2}$ tension affects oxygen saturation more than does arterial $\mathrm{O}_{2}$ tension. The authors reported that inhalation of $100 \% \mathrm{O}_{2}$ gas decreased perilymphic oxygen saturation, while inhalation of a mixture of $95 \% \mathrm{O}_{2}$ with $5 \% \mathrm{CO}_{2}$ increased perilymphic oxygen saturation. ${ }^{10}$

Likewise, Fisch et al $^{17}$ reported that carbogen inhalation increases inner ear oxygen saturation as measured by perilymphic oxygen saturation. Furthermore, Kallinen et al ${ }^{18}$ reported that carbogen inhalation is an effective treatment for high frequency hearing loss, although there was no significant difference in RHG in frequencies between patients receiving carbogen and those receiving Lipo-PGE1 in this study.

In conclusion, SHL has a variety of causes and is currently treated with combination modalities. Our findings suggest that efficacy of carbogen inhalation treatment is positive and it can be beneficial and additive to relative hearing gain and hence better hearing outcome.

We also found that there is significant association between age of onset of sensorineural hearing loss and betterment of hearing. Younger the age at the time of onset of hearing loss, there are better chances of hearing gain towards normal hearing sensitivity.

\section{CONCLUSION}

There is no definite treatment protocol available at present for ISSNHL, most accepted treatment modality being systemic steroids. In our study, we conclude that carbogen therapy is a beneficial addition to steroids in the treatment of sudden sensorineural hearing loss. 


\section{REFERENCES}

[1] Arts HA. Sensorineural hearing loss in adults. In: Flint PW, edr. Cummings Otolaryngology: head \& neck surgery. $5^{\text {th }}$ edn. Philadelphia: Mosby 2010: p. 2117-30.

[2] De Kleyn A. Sudden complete or partial loss of function of the octavus-system in apparently normal persons. Acta Otolaryngol 1944;32(5-6):407-29.

[3] Byl FM Jr. Sudden hearing loss: eight years' experience and suggested prognostic table. Laryngoscope 1984;94(5 Pt 1):647-61.

[4] Hughes GB, Freedman MA, Haberkamp TJ, et al. Sudden sensorineural hearing loss. Otolaryngologic Clinics of North America 1996;29(3):393-405.

[5] Fetterman BL, Luxford WM, Saunders JE. Sudden bilateral sensorineural hearing loss. Laryngoscope 1996;106(11):1347-50.

[6] Mattox DE, Simmons FB. Natural history of sudden sensorineural hearing loss. Ann Otol Rhinol Laryngol 1977;86(4 Pt 1):463-80.

[7] Wilson WR, Byl FM, Laird N. The efficacy of steroids in the treatment of idiopathic sudden hearing loss. A double-blind clinical study. Arch Otolaryngol 1980;106(12):772-6.

[8] Cinamon U, Bendet E, Kronenberg J. Steroids, carbogen or placebo for sudden hearing loss: a prospective double-blind study. Eur Arch Otorhinolaryngol 2001;258(9):477-80.

[9] Stokroos RJ, Albers FW, Tenvergert EM. Antiviral treatment of idiopathic sudden sensorineural hearing loss: a prospective, randomized, double-blind clinical trial. Acta Otolaryngol 1998;118(4):488-95.
[10] Kallinen J, Didier A, Miller JM, et al. The effect of CO2and 02-gas mixtures on laser Doppler measured cochlear and skin blood flow in guinea pigs. Hear Res 1991;55(2):255-62.

[11] Shea JJ, Kitabchi AE. Management of fluctuant hearing loss. Arch Otolaryngol 1973;97(2):118-24.

[12] Ni Y, Zhao X. Carbogen combined with drugs in the treatment of sudden deafness. Lin Chuang Er Bi Yan Hou Ke Za Zhi 2004;18(7):414-5.

[13] Ahn JH, Kim MR, Kim HC. Therapeutic effect of lipoprostaglandin E1 on sudden hearing loss. Am J Otolaryngol 2005;26(4):245-8.

[14] Westerlaken BO, de Kleine E, van der Laan B, et al. The treatment of idiopathic sudden sensorineural hearing loss using pulse therapy: a prospective, randomized, double-blind clinical trial. The Laryngoscope 2007;117(4):684-90.

[15] Lee HJ, Park CY, Lee JH, et al. Therapeutic effects of carbogen inhalation and lipo prostaglandin E1 in sudden hearing loss. Yonsei Med J 2012;53(5):9991004.

[16] Chaturvedi RC, Rai RM, Sharma RK. Therapeutic role of carbogen in impaired hearing. Indian J Med Res 1990;92:420-3.

[17] Fisch U, Murata K, Hossli G. Measurement of oxygen tension in human perilymph. Acta Otolaryngol 1976;81(3-4):278-82.

[18] Kallinen J, Laurikainen E, Laippala P, et al. Sudden deafness: a comparison of anticoagulant therapy and carbogen inhalation therapy. Ann Otol Rhinol Laryngol 1997;106(1):22-6. 